\title{
Constitutional recognition: U.S. perspective
}

\author{
April Denn \\ University of Technology Sydney, Faculty of Arts and Social Sciences, PO Box 123, Ultimo NSW \\ 2017, Australia. apriljeanne.denn@student.uts.edu.au
}

DOI: https://doi.org/10.5130/nesais.v4i1.1536

Urgency for the constitutional recognition of Aboriginal and Torres Strait Islander people is a complex problem where numerous issues must be considered. One concern is that Aboriginal people do not unanimously want constitutional recognition due to past understanding of how the 1967 Referendum intent to change Indigenous lifestyles and minimise the various hardships ended with unfilled expectations. It is important to learn from history and understand past faults. For example, the Constitution has defined Aboriginal people as a 'race' in Section 51(xxvi):

The Parliament shall, subject to this Constitution, have power to make laws for the peace, order, and good government of the Commonwealth with respect to: (xxvi) the people of any race, other than the aboriginal race in any State, for whom it is deemed necessary to make special laws;

Langton (2013) argues that defining Aboriginal people as a 'race' sets up the conditions for Indigenous people to be treated differently and ultimately as incapable of joining the Australian polity and society. This instance where Aboriginal people were defined by race and used in the Constitution only resulted in the detriment of their people instead of for the use of peace. I worry if constitutional recognition defines Aboriginal people by race, another solution must be the considered. I believe a Treaty is the most efficient mechanism for recognition and the best catalyst for change.

Being a United States citizen, I am aware that the United States government negotiated over 500 treaties with multiple tribes of the Native American people. The Australian government not taking part in a single Treaty between itself and the Aboriginal people is incongruous with the progressive nature of Australian society. I believe it is time for a Treaty, an imperative peacemaking tool all other Commonwealth countries have with their Indigenous communities.

A Treaty between the Australian government and the Aboriginal people can provide many of the Aboriginal demands that have been disregarded by the government in the past, most importantly recognition. In 'The Politics of Recognition', Charles Taylor (1992) argues that recognition is essential to one's identity. Relating this to Aboriginal affairs, I conclude the lack of acknowledgment will continue to contribute to Aboriginal people facing many problems that will never cease without such recognition. A Treaty would recognize Aboriginal people as the original owners of the land as well as acknowledge their sovereignty. By reclaiming their sovereignty, this sets up a platform for the 
Aboriginal people to be, in essence, their own nation, which includes important self-determination concepts such as self-government and cultural individuality.

A limitation to consider is who the government would form the Treaty with, as there are many Aboriginal tribes and communities. Although in theory it seems difficult for the Australian government to make treaties with each individual tribe, historically it was done in the United States. It is not unrealistic to compose multiple treaties, if peace and reconciliation is the true goal of the Australian government.

\section{References}

Langton, M., 2013, Indigenous Exceptionalism and the Constitutional 'Race Power', published in Space, Place and Culture.

Taylor, C. 1992, 'The Politics of Recognition' in Multiculturalism and "the Politics of Recognition": An Essay, Princeton University Press, pp. 25-73.

(c) (i) 2018 by the author(s). This article is distributed under the terms and conditions of the Creative Commons Attribution license (http://creativecommons.org/licenses/by-nd/4.0/). 